\title{
Study of Polycystic Ovaries (PCO) in Mymensingh Medical College Hospital, Bangladesh
}

\author{
K NAHAR $^{\mathrm{a}}$, H YASMIN ${ }^{\mathrm{b}}$, L PRAMANIK ${ }^{\mathrm{c}}$
}

Summary:

Background information: Polycystic ovaries (PCO) and their clinical expression (polycystic ovary syndrome) are conditions characterized by menstrual abnormality, clinical and biochemical features of hyperandrogenism. It is the killer of womanhood. Woman of any ethnic background can present with PCOS.

Objectives: To find out demographic characteristics such as age, BMI, clinical presentations like hirsutism, menstrual cycle pattern and fertility status and the hormonal changes like LH/FSH ratio and serum testosterone level.

Study design: A descriptive cross sectional study for 1 year from December 2009 to November 2010.

Study setting: Outdoor Department of obstetrics and gynaecology and center for Nuclear Medicine and Ultrasonography (CNMU) Mymensingh Medical College Hospital, Mymensingh.

Introduction:

Polycystic ovary syndrome is the most frequently encountered endocrinopathy in women of reproductive age. It is associated with significant morbidity in terms of both reproductive and non-reproductive events ${ }^{1}$.

The condition was first described in 1935 by Stein and Leventhal as a syndrome manifested by amenorrhoea, hirsutism and obesity associated with enlarged polycystic ovary ${ }^{2}$.

According to Rotterdam Criteria a refined definition of PCOS was the presence of two out of the following three criteria.

1. Oligomenorrhoea/or anovulation.

2. Hyperandrogenism (clinical and/or biochemical).

a. Prof. (Dr.) Kamrun Nahar, Professor \& Head Dept. of Gyane \& Obs, Green Life Medical College \& Hospital, Green Road, Dhaka.

b. Dr. Halima Yasmin, Medical Officer, Upazilla Health Complex, Phulpur, Mymensingh.

c. Dr. Lita Pramanik, Consultant, Eshorganj Upazilla Health Complex, Mymensingh.

Address of Correspondence: Prof. (Dr.) Kamrun Nahar, E-mail: run@btcl.net.bd Mobile No: 0088-01711689778

Received: 01 June, 2013

Accepted: 12 January, 2014
Result: Total 55 patients were evaluated. Most common age was 20-29 years (72.7\%) with mean age 23.55 years and mean BMI $27.12 \mathrm{~kg} /{ }^{\mathrm{m} 2}$. Clinical presentations were in this study hirsutism in $36.4 \%$, irregular menstrual cycle in $63.6 \%$ and subfertility in $56.3 \%$. Laboratory findings revealed testosterone level was more than normal range in $58 \%$ case, LH/FSH ratio was increased (more than $1: 1$ ) in $58.2 \%$ cases, 26 cases had both increased testosterone level and increased LH/FSH ratio. 17cases had testosterone level within normal range and LH/FSH ratio less than 1:1.

Conclusion: There are significant relationship between irregular menstrual cycle pattern and hormonal changes such as testosterone level and LH/FSH ratio. There are also significant relationship between BMI and hirsutism with increased testosterone level.

Keywords: Polycystic ovary, irregular menstrual cycle, Hirsutism, subfertility LH/FSH ratio, testosterone level.

(J Banagladesh Coll Phys Surg 2014; 32: 142-148)

3. Polycystic ovaries with the exclusion of other aetiologies ${ }^{3}$.

Polycystic ovaries are seen at ultrasound in $20-25 \%$ women of reproductive age while PCOS occurs at least $4-6 \%$ of the population. The prevalence of polycystic ovary syndrome seems to be rising because of the current epidemic of obesity ${ }^{3}$.

Women of any ethnic background can present with PCOS. $4 \%$ to $4.7 \%$ of white women and $3.4 \%$ of African American women had PCOS ${ }^{4}$.

The aetiology of PCO is uncertain. There is some evidence of autosomal transmission related to strong familiar clustering. It also represents a complex trait in which a small number of major genes interact with environmental and other genetic factor to account for the heterogeneity ${ }^{5}$.

Family study has revealed that about $50 \%$ of first degree relatives have PCOS suggesting a dominant mode of inheritance ${ }^{6}$.

Although USG finding of PCO present in women but of them $66 \%$ notice abnormal menstrual pattern ${ }^{7}$. The menstrual cycle abnormality ranges from amenorrhoea, oligomenorrhoea to menorrhagia. Patient with PCOS 
may experience endometrial hyperplasia. About 15\% to $30 \%$ of women with PCOS may have regular cycle in spite of anovulation ${ }^{4}$.

Infertility is a common problem in women with PCOS. The syndrome accounts for $90-95 \%$ of women who attend infertility clinics ${ }^{8}$. The chance of pregnancy with PCOS women using fertility treatment is very good ${ }^{9}$.

The prevalence of obesity is high in patient with PCOS. The rate of obesity in PCOS population ranges from $38 \%$ to $87 \%$. The cause of obesity in PCOS is not fully known. The obesity of PCOS is of the android type (central type). There is an increased waist to hip ratio associated with hyperandrogenemia, insulin resistance, glucose intolerance and dyslipidemia ${ }^{10}$.

Excessive hair growth is the most distinction and visible feature of PCOS. The hair growth usually are seen on the face, upper lip, chin and lower abdomen as an extension of pubic hair towards the umbilicus. Women with PCOS may experience increase skin oiliness secondary to excessive stimulation of the pilosebaceous unit. Acanthosis nigricans appears as symmetrical darkness that appears commonly on the nape of the neck ${ }^{11}$.

PCOS are most often diagnosed by means of laboratory studies. The ratio of the $\mathrm{LH}$ to the FSH level is useful in the diagnosis. The ratio of LH to FSH is greater than $1: 1$, as tested on day 3 of the menstrual cycle. This change in LH to FSH ratio is enough to disrupt ovulation $^{12}$.

Serum level of androgens including androstenedione, testosterone and dehydro-epiandrosterone sulfate may be elevated. The free testosterone level is thought to be the best means ${ }^{13}$. Total testosterone ranges are 6-86 ng/ $\mathrm{dl}$. Free testosterone refers to the amount of testosterone that is unbound and actually active and its ranges from 0.7-3.6 ng/dl. Women with PCOS often have an increased level of both total testosterone and free testosterone $\mathrm{e}^{12}$.

According to the Rotterdam criteria the ultrasonic feature of PCO are defined and include either 12 or more follicles, measuring 2-9 $\mathrm{mm}$ in diameter and increased ovarian volume $>10 \mathrm{~cm}^{3}$. It is essential that the ultrasound scans is performed at a time of ovaries quiescence such as during the early follicular phase of the menstrual cycle ${ }^{14}$.

\section{Meterial and Methods:}

It is Descriptive cross-sectional study conducted in the outdoor Department of Obstetrics \& Gyneacology and Center for Nuclear Medicine and Ultrasonography (CNMU) Mymensingh Medical College Hospital, Mymensingh for one year duration from December 2009 to November 2010. The present study includes the women of reproductive age (15 years to 45 years) who sonographically show PCO, excluding the woman with other medical disorders like ovarian tumour, hypothyroidism and hyperprolactinoma. Purposive sampling technique was followed for selection of sample.

Measurement of LH, FSH and Testosterone Level: $5 \mathrm{ml}$ venous blood was collected from each subject with all aseptic precaution using sterile disposable plastic syringe by anticubital venipuncture and poured into a clean glass test tube. The collected blood was allowed to clot at room temperature. Serum was separated and taken in other three plastic test tube. Each test tube is leveled separately for LH, FSH and testosterone. Antibody of LH, FSH and testosterone were added to these serum and mixed well. Then these test tube are kept for 2 hours at $37^{0} \mathrm{C}$ temperature. After that $\mathrm{I}^{125}$ were added to these test tube and incubated at $4^{0}-7^{0} \mathrm{C}$ temperature. Duration of incubation time was different for each hormone. After that incubation time the serum was kept in room temperature for 30 minutes. Then 500 microliter precipitating solution was added in each test tube and mixed well. These test tube were kept in centrifuge machine and centrifuge it at $3500 \mathrm{Rpm}$. Precipitant were appeared at the bottom test tube. The level of these hormones were measured from these Precipitant.

Transabdominal ultrasonography was performed with 3.5MHz curvilinear electronic probe in the Center for Nuclear Medicine and Ultrasonography (CNMU), $\mathrm{MMCH}$ to all the women of this study in full bladder. The diagnosis of PCO was done by ovarian volume (e"10 $\mathrm{cm}^{3}$ ), stromal echotexture and follicular number $(>10)$.

Data were collected using a structured questionnaire containing all the variables of interest. Collected data were processed and analyzed using computer based software SPSS (Statistical Package for Social Sciences) version 12 . A probability value of $<0.05$ was considered significant. The summarized data were presented in the form of tables and graphs with due interpretation. 


\section{Results:}

Fifty five (55) women with PCO were selected from outdoor department of Obs and Gynae MMCH having USG report from Centre for Nuclear Medicine and Ultrasonography $\mathrm{MMCH}$ during the period of December 2009 to November 2010. All cases were evaluated clinically (age, BMI, hirsutism, menstrual cycle pattern and fertility status). Hormonal level (LH/ FSH ratio and total testosterone level) were done for all cases.

The findings and related interpretation are presented in tables and figures according to the objectives of the study.

Table-I: Respondents by age: Regarding age distribution of the respondents in the study group it was observed that most of the women were within 20-29 years (72.7\%).

\section{Table-I}

\begin{tabular}{lcc} 
& Respondents by age. \\
Age (Years) & Numbers & Percentage \\
\hline $15-19$ & 09 & 16.4 \\
$20-24$ & 22 & 40.0 \\
$25-29$ & 18 & 32.7 \\
$30-34$ & 05 & 9.1 \\
$>35$ & 01 & 1.8 \\
\hline Total & 55 & 100.0 \\
\hline
\end{tabular}

Mean \pm SD of age distribution was $23.55 \pm 4.62$ years.

Table-II: Respondents on the basis of BMI: Most of the respondents 26 (47.3\%) were over weight (BMI 25.1$\left.30 \mathrm{~kg} / \mathrm{m}^{2}\right), 12(21.8 \%)$ were obese having BMI more than $30 \mathrm{~kg} / \mathrm{m}^{2} \& 17(30.9 \%)$ cases had normal BMI. Mean \pm SD of BMI was $27.12 \pm 3.52 \mathrm{~kg} / \mathrm{m}^{2}$.

Table-II

\begin{tabular}{lcc}
\multicolumn{3}{c}{ Respondents on the basis of BMI. } \\
BMI $\left(\mathrm{kg} / \mathrm{m}^{2}\right)$ & Numbers & Percentage \\
\hline $20.0-25$ & 17 & 30.9 \\
$25.1-30.0$ & 26 & 47.3 \\
$>30.1$ & 12 & 21.8 \\
\hline Total & 55 & 100.00 \\
\hline
\end{tabular}

Table-III: Respondents by hirsutism: Hirsutism was present in 20 (36.4\%) cases and absent in 35 (63.6\%) cases.

\section{Table-III}

\begin{tabular}{lcc} 
& Respondents by hirsutism. & \\
Hirsutism & Numbers & Percentage \\
\hline Present & 20 & 36.4 \\
Absent & 35 & 63.6 \\
\hline Total & 55 & 100.00 \\
\hline
\end{tabular}

Table-IV: Respondents by menstrual cycle pattern: 31 (56.3\%) women were presented with oligomenorrhoea and 03 (5.5\%) women had amenorrhoea. Here 35(63.6\%) women had irregular menstrual cycle. On the other hand 20 (36.4\%) women had regular menstrual cycle.

\section{Table-IV}

\section{Respondents by menstrual cycle pattern.}

\begin{tabular}{lcc} 
Menstrual cyclepattern & Numbers & Percentage \\
\hline Regular & 20 & 36.4 \\
Oligomenorrhoea & 31 & 56.3 \\
Amenorrhoea & 03 & 5.5 \\
Menorrhagia & 01 & 1.8 \\
\hline Total & 55 & 100.00 \\
\hline
\end{tabular}

Table-V: Respondents by fertility status: Regarding fertility status of the women, primary subfertility was found in 28 (50.8\%) cases and secondary subfertility was found in 03 (5.5\%) cases. Total subfertility cases were 31 (56.3\%). Satisfactory fertility was present in 9 (16.4\%) cases. Fertility status of 15 (27.3\%) respondents was not concerned as they were unmarried.

Table-V

\section{Respondents by fertility status.}

\begin{tabular}{lcc} 
Fertility status & Numbers & Percentage \\
\hline Fertile & 09 & 16.4 \\
Primary subfertility & 28 & 50.8 \\
Secondary subfertility & 03 & 5.5 \\
Not concern & 15 & 27.3 \\
\hline Total & 55 & 100.00 \\
\hline
\end{tabular}


Fig-1: The testosterone level \& LH/ FSH ratio of the respondents: 26 women had LH/FSH ratio more than 1:1 and testosterone level more than normal limit. 17 women had LH/ FSH ratio at or less than 1:1 and testosterone level within normal limit.

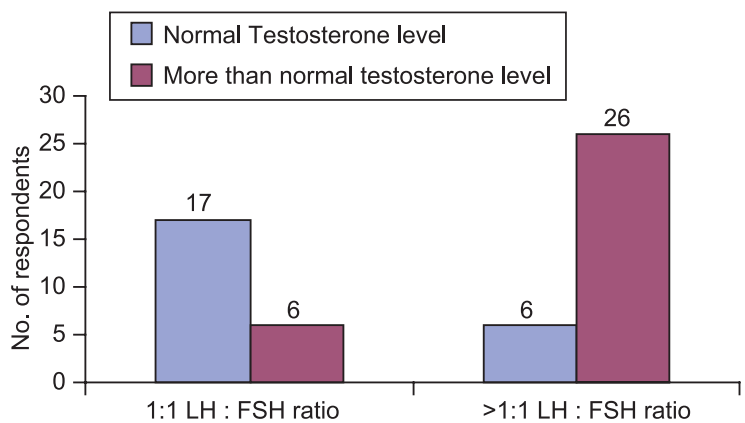

Fig-1: The testosterone level \& LH/ FSH ratio of the respondents.

Table -VI: Relationship between menstrual cycle pattern with levels of testosterone $(\mathrm{N}=54)$ :

In case of menstrual cycle pattern, 29 (53.8\%) women with oligomenorrhoea and 2 (3.7\%) women with amenorrhoea had increased testosterone level. The relationship between menstrual cycle pattern and testosterone level was also statistically significant $\left(\mathrm{X}^{2}\right.$ $=39.31$, $\mathrm{df}=2$, $\mathrm{p}$ value $<0.05$ ).

Table-VII: Relationship between BMI, hirsutism and fertility status with levels of testosterone $(\mathrm{N}=55)$ : 27 (49\%) women with increased BMI $\left(>25 \mathrm{~kg} / \mathrm{m}^{2}\right)$ had increased testosterone level. The overall relationship between BMI and level of testosterone was statistically significant. 16(29\%) women with hirsutism had increased testosterone level. The relationship between the present or absent of hirsutism with testosterone levels were statistically significant $\left(X^{2}=6.149, \mathrm{df}=1, \mathrm{p}\right.$ value $<0.05)$. 15(27.5\%) women with primary subfertility and $1(1.8 \%)$ women with secondary subfertility had increased testosterone level. Fertility status with testosterone level were statistically non-significant.

Table-VIII: Relationship between menstrual cycle pattern with LH/FSH ratio (N=54): For menstrual cycle pattern, 25(46.4\%) women with oligomenorrhoea and 2(3.6\%) women with amenorrhoea had LH/FSH ratio more than 1:1. The relationship between menstrual cycle pattern and LH/FSH ratio was statistically significant $\left(X^{2}=16.96, d f=2\right.$, $p$ value $<0.05$ ).

Table-IX: Relationship between BMI, hirsutism and fertility status with $\mathrm{LH} / \mathrm{FSH}$ ratio $(\mathrm{N}=55)$ : Though more

Table-VI

\begin{tabular}{|c|c|c|c|c|}
\hline \multicolumn{5}{|c|}{ Relationship between menstrual cycle pattern with levels of testosterone $(N=54)$. } \\
\hline \multirow{2}{*}{$\begin{array}{l}\text { Menstrual Cycle } \\
\text { Pattern }\end{array}$} & \multicolumn{2}{|c|}{ Testosterone (n \%) } & \multirow{2}{*}{$X^{2}$ (df) } & \multirow{2}{*}{ p-value } \\
\hline & Normal & $>$ Normal & & \\
\hline Regular & 19 (35.2) & $1(1.8)$ & $39.31(2)$ & 0.000 \\
\hline Oligomenorrhoea & $2(3.7)$ & 29 (53.8) & & \\
\hline Amenorrhoea & $1(1.8)$ & $2(3.7)$ & & \\
\hline Total= $54(100 \%)$ & $22(40.7)$ & 32 (59.3) & & \\
\hline
\end{tabular}

Table-VII

Relationship between BMI, hirsutism and fertility status with levels of testosterone $(N=55)$.

\begin{tabular}{|c|c|c|c|c|c|}
\hline \multicolumn{2}{|c|}{ Clinical Characteristics } & $\frac{\text { Testosterone (n \%) }}{>\text { Normal }}$ & $X^{2}(\mathrm{df})$ & p-value & \\
\hline BMI & $\begin{array}{l}\text { Normal } \\
20-25 \mathrm{~kg} / \mathrm{m}^{2} \\
>25 \mathrm{~kg} / \mathrm{m}^{2} \\
\text { Total }=55(100 \%)\end{array}$ & $\begin{array}{l}>\text { Normal } \\
12(22.0) \\
11(20.0) \\
23(42.0)\end{array}$ & $\begin{array}{l}05(09.0) \\
27(49.0) \\
32(58.0)\end{array}$ & $8.371(1)$ & 0.004 \\
\hline Hirsutism & $\begin{array}{l}\text { Present } \\
\text { Absent } \\
\text { Total= 55(100\%) }\end{array}$ & $\begin{array}{c}4(7.0) \\
19(34.54) \\
23(41.54)\end{array}$ & $\begin{array}{l}16(29.0) \\
16(29.46) \\
32(58.46)\end{array}$ & $6.149(1)$ & 0.013 \\
\hline Fertilitystatus & $\begin{array}{l}\text { Primary subinfertility } \\
\text { Secondary subfertility } \\
\text { Others }\end{array}$ & $\begin{array}{c}13(23.6) \\
2(3.6) \\
8(14.5)\end{array}$ & $\begin{array}{c}15(27.5) \\
1(1.8) \\
16(29.0)\end{array}$ & $1.76(2)$ & 0.424 \\
\hline & Total= $55(100 \%)$ & $23(41.7)$ & $32(58.3)$ & & \\
\hline
\end{tabular}




\section{Table-VIII}

\section{Relationship between menstrual cycle pattern with LH/FSH ratio $(N=54)$.}

\begin{tabular}{lcccc} 
Menstrual cycle pattern & \multicolumn{2}{c}{ LH: FSH (n \%) } & $X^{2}(\mathrm{df})$ & p-value \\
\hline & $\leq 1: 1$ & $>1: 1$ & & \\
Regular & $15(27.8$ & $05(9.3)$ & $16.96(2)$ & 0.001 \\
Oligomenorrhoea & $6(11.1)$ & $25(46.4)$ & & \\
Amenorrhoea & $1(1.8)$ & $2(3.6)$ & \\
\hline Total= 54(100\%) & $22(40.7)$ & $32(59.3)$ & & \\
\hline
\end{tabular}

Table-IX

\begin{tabular}{|c|c|c|c|c|c|}
\hline \multicolumn{6}{|c|}{ Relationship between BMI, hirsutism and fertility status with $L H / F S H$ ratio $(N=55)$. } \\
\hline \multicolumn{2}{|c|}{ Clinical Characteristics } & \multirow{2}{*}{$\begin{array}{c}\text { LH: FSH (n \%) } \\
>1: 1\end{array}$} & \multirow[t]{2}{*}{$X^{2}(\mathrm{df})$} & \multicolumn{2}{|l|}{ p-value } \\
\hline & $\leq 1: 1$ & & & & \\
\hline \multirow[t]{3}{*}{ BMI } & $20-25 \mathrm{~kg} / \mathrm{m}^{2}$ & $09(16.4)$ & $08(14.5)$ & $1.251(1)$ & 0.263 \\
\hline & $>25 \mathrm{~kg} / \mathrm{m}^{2}$ & $14(25.5)$ & $24(43.6)$ & & \\
\hline & Total $=55(100 \%)$ & $23(41.9)$ & $32(58.1)$ & & \\
\hline \multirow[t]{3}{*}{ Hirsutism } & Present & $5(9.0)$ & $15(27.0)$ & $3.654(1)$ & 0.056 \\
\hline & Absent & $18(33.0)$ & $17(31.0)$ & & \\
\hline & Total $=55(100 \%)$ & $23(42.0)$ & $32(58.0)$ & & \\
\hline \multirow[t]{4}{*}{ Fertility status } & Primary subfertility & $12(22.0)$ & $16(29.2)$ & $.958(2)$ & 0.505 \\
\hline & Secondary subfertility & $2(3.6)$ & $1(1.8)$ & & \\
\hline & Others & $9(16.4)$ & $15(27.0)$ & & \\
\hline & Total=55 (100\%) & $23(42.0)$ & $32(58.0)$ & & \\
\hline
\end{tabular}

than $40 \%$ women had increased BMI and increased LH/ FSH ratio, but statistically the relationship between BMI and LH/FSH ratio was not significant. 15(27\%) women with hirsutism and 16(29.2\%) women with primary subfertility had increased LH/FSH ratio. The relationship between the present or absent of hirsutism and fertility status of the women with $\mathrm{LH} / \mathrm{FSH}$ ratio were also statistically non-significant.

\section{Discussion:}

Polycystic ovaries are seen by USG finding in 20-25\% women of reproductive age. PCOS occur in at least $5 \%$ women of the population. Polycystic ovaries can be diagnosed in patient of any age from menarche. Typically women in their 20s present with polycystic ovary syndrome ${ }^{15}$. In present study among 55 women, $72.7 \%$ were within the age of 20-29 years. The mean age was 23.55 years. In another study, the mean \pm SD of age distribution was $21.9 \pm 3.06^{16}$, which is nearer to present study. A recent study showed that the common age of PCO women were $21-25$ years ${ }^{17}$. This result is also close to the present study.

In the present study, thirty eight out of the fifty five women were overweight and obese with mean BMI of $27.12 \pm 3.52 \mathrm{~kg} / \mathrm{m}^{2}$. In another study mean BMI was $27.1 \mathrm{~kg} / \mathrm{m}^{2} 17$. Mean BMI of PCO women were 28.98 $\mathrm{kg} / \mathrm{m}^{2}$ in an Indian study ${ }^{16}$. Both the results are nearer to present study.

In the present study hirsutism was present in 36.4\% cases. In a study at BSMMU 50\% women had hirsutism ${ }^{17}$. The percentage was more than the present study because asymptomatic women with PCO were included. The presence of hirsutism was significant among women with PCO than without PCO in an Indian study ${ }^{18}$. 
The common presentation of the women having PCO was menstrual disturbance ${ }^{7}$. In the present study out of 55 women, 35 (63.6\%) women attended in outdoor department with irregular menstrual cycle.

Among them 56.3\% women had oligomenorrhoea. The study at BSMMU showed that women with PCOS had oligomenorrhoea in $28 \%$ cases $^{17}$. The percentage was less than the present study. In a study in Iraq, oligomenorrhoea was prevalent in $43.93 \%$ women, nearer to the present study ${ }^{19}$.

56.3\% women with PCO attended in outdoor department due to subfertility (both primary and secondary) during the study time period. Among them about 28 (50.8\%) women had primary subfertility and 3(5.5\%) women had secondary subfertility. In the study of BSMMU, primary subfertility was found in $90 \%$ cases and secondary subfertility was found in $10 \%$ cases $^{17}$. According to a literature, 16-25\% of normal ovulatory women have polycystic ovaries without evidence of the syndrome, a subgroup of women with PCO (up to 30\%) may have PCOS ${ }^{1}$. In present study out of 55 women, $60 \%$ women had PCOS and $40 \%$ women had only PCO, not similar to the literature review.

In the present study, 58.2\% women with PCO had LH/ FSH ratio more than 1:1. Increased testosterone level was found in 58\% women with PCO. In an Indian study, $55.55 \%$ women had increased LH/FSH ratio and $64.44 \%$ women had increased testosterone level which is closed to present study ${ }^{16}$. $53.8 \%$ women with oligomenorrhoea and 3.7\% women with amenorrhoea had increase testosterone level in present study. The result is significant. In another study $73 \%$ girl with irregular menstrual cycle (oligomenorrhoea and amenorrhoea) had the highest androgen level, nearer to present study ${ }^{17}$.

In the present study $49 \%$ cases with increased testosterone level were over weight and obese $\left(\mathrm{BMI}>25 \mathrm{~kg} / \mathrm{m}^{2}\right)$ and $20 \%$ cases with normal testosterone level were overweight and obese. The result is significant. Increased testosterone levels among overweight and obese women were found in 59.18\% cases in another study ${ }^{16}$. The result of the present study is nearer to this study.

In the present study hirsutism was present in 36.4\% cases. In relation with hirsutism and testosterone level,
$29 \%$ women with increase testosterone level had hirsutism whereas $7 \%$ women with normal testosterone level had hirsutism. The result is significant. In an Indian study, $44.2 \%$ women with hirsutism had significantly high testosterone level ${ }^{16}$. The result is more than the present study.

In the present study $27.5 \%$ women with primary subfertility and $1.8 \%$ women with secondary subfertility had increased testosterone level. The result is not significant. Other study showed $36 \%$ subfertile women with PCO and $28 \%$ subfertile women without PCO had increased testosterone level ${ }^{21}$. So their result supports present study.

In the relation between menstrual cycle pattern and $\mathrm{LH} /$ FSH ratio, 46.4\% women with oligomenorrhoea and $3.6 \%$ women with amenorrhoea had increase LH/FSH ratio in present study and $11.1 \%$ women with oligomenorrhoea and $1.8 \%$ women with amenorrhoea had LH/FSH ratio at or less than 1:1. The result is significant. Study in Iraq about correlation between LH/ FSH ratio and disease menifestation showed no significant correlation between menstrual cycle pattern and $\mathrm{LH} / \mathrm{FSH}$ ratio ${ }^{20}$.

In present study $43.6 \%$ obese and overweight women had $>1: 1 \mathrm{LH} / \mathrm{FSH}$ ratio. On the other hand 25.5\% obese and overweight women had at or less than 1:1 LH/FSH ratio. The result is not significant. In a study in Iraq, they also found that there was no significant correlation between BMI and LH/FSH ratio ${ }^{20}$. This result has similarity to present result.

About the correlation between hirsutism and LH/FSH ratio, $27 \%$ women with hirsutism had increased LH/ FSH ratio and 9\% women with hirsutism had LH/FSH ratio at or below 1:1. The result is not significant. Statistical correlation between LH/FSH ratio and hirsutism was not significant in a study in Iraq ${ }^{20}$.

In the present study, 29.2\% women with primary subfertility and $1.8 \%$ women with secondary subfertility had LH/FSH ratio more than $1: 1$. Whereas $22 \%$ women with primary subfertility and $3.6 \%$ women with secondary subfertility had LH/FSH ratio at or less than 1:1. The result was not significant. Another study had increased LH/FSH ratio in 60\% subfertile women with PCO and $70 \%$ women without PCO ${ }^{21}$. So their result supports the present study. 
The required size was not possible to collect because of limitation of time and financial constrains. All the facts and figures mentioned here may considerably vary from those of large series covering wide range of time.

\section{Conclusion:}

Irregular menstruation, increased BMI, hirsutism and subfertility are the common presentation of women with PCOS. There are significant relationship between irregular menstrual cycle pattern and hormonal changes such as testosterone level and LH/FSH ratio. There are also significant relationship between BMI and hirsutism with increased testosterone level. Common future outcome of PCOS are type 2 diabetes mellitus, hypertension, cardiovascular disease and endometrial carcinoma. Early diagnosis and proper preventive management of these patients with PCO will reduce reproductive and non reproductive morbidity.

\section{References:}

1. Carmina, E. and Lobo, R.A. Polycystic ovary syndrome (PCOS): Arguably the most common endocrinopathy is associated with significant morbidity in women. The Journal of clinical Endrocrinology \& Metabolism, 1999; 84(6): 18971899.

2. Dutta, D.C. Text book of Gynecology including contraception. 5th ed. Kolkata, India: New Central Book Agency (P) Ltd. 2009; 440-443.

3. Kumar, P. and Malhotra, N. Jeffcoatee's Principles of Gynecology.7th ed. New Dilhi: Jaypee Brothers Medical Publishers (P) Ltd. 2008; 384-393.

4. Attaran, M., 2009. Polycystic ovary syndrome. Publications: disease management project center for continuing education.[ Online] Available at http://www.clevelandclinicmeded.com/ medicalpubs/diseasemanagement/womens- Health[Accessed 1 Jan 2009]

5. Hopkinson, Z.E., Sattar, N., Fleming, R. and Green, I.A. Polycystic ovarian syndrome: the metabolic syndrome comes to gynecology. BMJ, 1998; 317: 329-332.

6. Balen, A.H., 2007. Polycystic ovary syndrome and secondary amenorrhoea. In: D.K.Edmond, ed. Dewhourt's text book of obstetrics and gynecology. 17th ed. Oxford: Blackwell Publishing Ltd.Ch.39.

7. Cahill, D., 2009. Polycystic ovary syndrome (PCOS). Women's Health Net doctor.[Online] Available at http:// www.netdoctor.co.uk/womenshealth/facts/pcos.htm

[Accessed 14 December 2009]

8. Editorial. Should obese women with polycystic ovary syndrome receive treatment for infertility? BMJ, 2006; 332: 434-435.
9. Advanced Fertility center, 2010. Polycystic ovarian synd rom, PCOS and infertility and pregnancy what is PCOS syndrom. Chicago: Advanced Fertility center. [Online] Available from http://www.advancedfertility.com/PCOS.htm [Accessed 11 January 2010]

10. Ehrmann, D.A. Polycystic ovary syndrome. The New England Journal of Medicine, 2005; 352: 1233-1236.

11. Chang, R. and Kazer, R., 2008. Polycystic ovary syndrome. Glob. Libr. Women's med [Online] Available from http:// www.glow m.com/? p = glowm.cml/s ection iew\&artical=300\&SESSID=rtk2svqrc [Accessed 30 October 2010]

12. Sterling, E., 2010, Hormone levels and PCOS. OBGYN. Net: The Universe of Women's Health, [Online] Available from www.obgyn.net/pcos/pcos.asp? page =/pcos/articles/ hormone-level-sterling [Accessed 31 August 2010].

13. Wikipedia, 2010. Polysystic ovary syndrome, Wikipedia, the free encyclopedia, [Online] Available from. http:// en.wikipedia.org/wiki/polycysticovarysyndrom [Accessed 11 July 2009]

14. Balen, A.H. et al. Ultrasound assessment of polycystic ovary:international consensus definition. Oxford Journal Medicine Human Reproduction Update, 2003; 9(6): 505-514.

15. Marrinan, G. and Stein, M., 2009. Polycystic ovarian disease (stein-leventhal syndrome) [Online] Available at http:// Emedicine medscape.com/ article/404754-overview [Accessed 11 August 2009]

16. Dipankar, B. et al. Clinical correlation with biochemical status in polycystic ovarian syndrome. The Journal of Obstetrics and Gynecology of India, 2005; 55(1): 67-71

17. Hooff, M.H. et al. Polycystic ovaries in adolescents and the relationship with menstrual cycle patterns, luteinizing hormone, androgens and insulin. The Official Journal of the American Society for Reproductive Medicine, 2000; 74(1): 49-58.

18. Anwary, S.A., Alfazzaman, M. and Begum, N. A clinical study on PCOS patients in a Tertiary Hospital. Medicine Today, 2009; 22(1): 34-37.

19. Zargar, A.H. et al. Prevelance of ultrasonography proved polycystic overies in North Indian Women with type 2 diabetes mellitus. Reproductive biology and Endrocrinology, 2005; 3: 35-45.

20. Alnakash, A.H. and Al-Tae'e, N.K. Polycystic ovarian syndrome: the correlation between the LH/FSH ratio and disease manifestations. Middle East fertility society Journal, 2007; 12(1): 35-39

21. Speranda, Z. and Papic, Z. Effect of increased testosterone level on women's fertility. Preliminary Communication, 2004; 33(2): 53-58

[Online] Available from http:/www.idb.hr/diabetologia/ 04no2-3pdf

[Accessed 11 January 2010]. 